\title{
A Novel Chemoattractant Lectin, Karatoxin, From the Dorsal Spines of the Small Scorpionfish Hypodytes rubripinnis
}

\author{
Mitsuko Shinohara ${ }^{1, *}$, Kuniko Nagasaka ${ }^{2}$, Hideyuki Nakagawa ${ }^{1,3}$, Kozue Edo $^{3}$, Hitomi Sakai ${ }^{3}$, Koji Kato ${ }^{1}$, \\ Futoshi Iwaki ${ }^{1}$, Kiyoshi Ohura ${ }^{1}$, and Haruhiko Sakuraba ${ }^{4}$ \\ ${ }^{1}$ Depatment of Pharmacology, Osaka Dental University, Hirakata 573-1121, Japan \\ ${ }^{2}$ Fukae Nagasaka Clinic, Etajima 737-2214, Japan \\ ${ }^{3}$ Department of Environmental Symbiosis, Institute of Socio-Arts and Sciences, \\ The University of Tokushima Graduate School, Tokushima 770-8502, Japan \\ ${ }^{4}$ Department of Applied Biological Sciences, Kagawa University, Kagawa 761-0795, Japan
}

Received February 22, 2010; Accepted June 16, 2010

\begin{abstract}
A chemoattractant lectin from the dorsal spines of the redfin velvetfish, Hypodytes rubripinnis, was isolated using a combination of affinity chromatography techniques. The glycoprotein, with a molecular mass of $110 \mathrm{kDa}$, is named Karatoxin. Karatoxin caused agglutination of rabbit erythrocytes. This agglutination was effectively inhibited by D-mannose. In addition, Karatoxin exhibited not only mitogenic activity in the presence of murine splenocytes, but also chemotactic activity in the presence of guinea-pig neutrophils and macrophages. Thus, Karatoxin appears to be a novel chemoattractant lectin. These results suggest that the redfin velvetfish Hypodytes rubripinnis may be a novel source of biologically active substances.
\end{abstract}

Keywords: chemoattractant lectin, Karatoxin, Hypodytes rubrinnis

The redfin velvetfish Hypodytes rubripinnis is a small congiopodid fish that belongs to the Scorpaenidae group, known as scorpionfish. However, H. rubripinnis is dangerous to man. The venom organs of $H$. rubripinnis consist of 14 dorsal, 2 pelvic, and 3 anal spines that contain venom glands, covered by an integumentary sheath, like other Scorpaenidae (1). Envenomation usually occurs due to mishandling of the fish when the force of contact with a spine causes it to pierce the flesh and exert sufficient pressure on the venom glands; this results in the dislodging of the stored venom, which flows along the spine into the subcutaneous tissue of the victim. The main symptom of envenomation is intense pain with severe muscle ache, and the area surrounding the puncture wound is swollen. Systemic effects include dyspnea and restlessness. For emergent treatment, physicians recommend infiltrations of the wound area with $0.5 \%-2.0 \%$ lidocaine and steroid ointment. In the event of shock, treatment includes the infusion of steroids $(100-200$ $\mathrm{mg}$ ) (2). However, there is little information available

*Corresponding author. shino@cc.osaka-dent.ac.jp Published online in J-STAGE on July 16, 2010 (in advance) doi: $10.1254 /$ jphs.10058SC regarding the biochemical and physiological properties of the venom from $H$. rubripinnis. More recently, we observed that Karatoxin, a glycoprotein purified from the dorsal venom, shows cytotoxic activity against murine P388 leukemia cells (2).

Lectins isolated from numerous plants and animals including invertebrates are generally defined as non-enzymatic proteins that play an important role in physiological functions $(3,4)$. In recent years, many lectins have also been isolated from marine sources $(5-7)$, but very few have been reported in marine animals, particularly fish (8). Here, we report the biological activities of Karatoxin as a novel chemoattractant lectin from the dorsal spine venom of spine $H$. rubripinnis.

Hypodytes rubripinnis (180 specimens, average size of $8 \mathrm{~cm}$ ) were collected by local fishermen from the coast of Hiroshima Prefecture, Japan in August 1999 (Fig. 1). The collected fish were transported live or frozen to our laboratory. The dorsal spines (total of 14) from each H. rubripinnis specimen were cut from their base. The dorsal spines with the integumentary sheath containing a fusiform strand of glandular tissue were extracted with $0.15 \mathrm{M} \mathrm{NaCl}$ followed by centrifugation at $2,000 \times \mathrm{g}$ for $20 \mathrm{~min}$ at $4^{\circ} \mathrm{C}$. The resulting supernatant was lyophilized. 


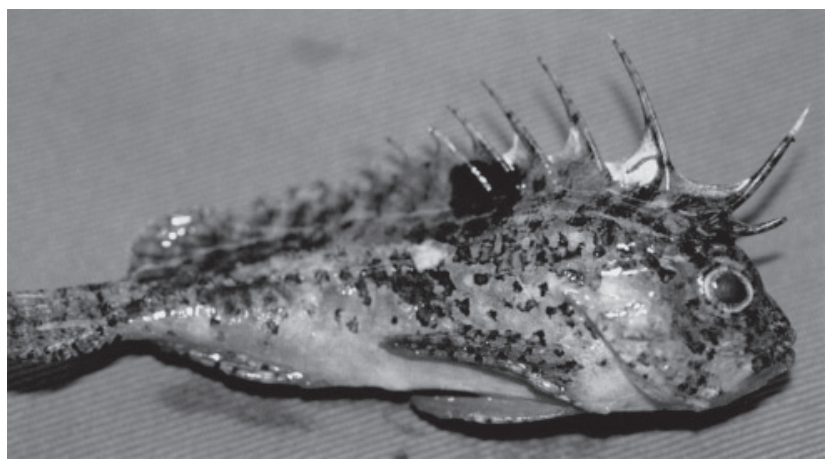

Fig. 1. Redfin velvetfish, Hypodytes rubripinnis; average size: $8 \mathrm{~cm}$.

The lyophilized venom was stored at $-80^{\circ} \mathrm{C}$ until use. The protein content was measured according to the method of Bradford (9) using bovine serum albumin as a standard.

Agglutinating activity was assayed using rabbit erythrocytes in microtiter plates. A $25-\mu 1$ aliquot of a $2 \%(\mathrm{v} / \mathrm{v})$ suspension of erythrocytes in $6.4 \mathrm{mM}$ phosphate-buffered saline (PBS) was added to $50 \mu \mathrm{l}$ of a serial two-fold dilution of the sample. The plates were incubated at room temperature for $1 \mathrm{~h}$. The results are expressed as the minimum concentration of the sample $(\mu \mathrm{g} / \mathrm{ml})$ required for positive agglutination.

Mitogenic activity in the presence of murine splenocytes was determined employing a cell culture assay using the MTT tetrazolium salt (3-[4,5-dimethyl thiazol2-yl]-2,5-diphenyl tetrazolium bromide) (10).Polymorphonuclear leukocytes (neutrophils) and macrophages were induced by the intraperitoneal injection of $1 \%$ glycogen solution into male guinea pigs and collected by centrifugation in PBS. The washed cells were resuspended in Dulbecco's modified Eagle's medium (DMEM) and adjusted to a neutrophil density of $2 \times 10^{6}$ cells $/ \mathrm{ml}$ and a macrophage density of $1 \times 10^{6}$ cells/ ml.Chemotaxis was measured employing a membrane filter method using a 48-well chemotaxis chamber (Neuroprove, Gaithersburg, MD, USA). A cell suspension was placed in the upper wells of a chamber separated by a polycarbonate membrane filter $(3-\mu \mathrm{m}$ pore size for neutrophils and $5-\mu \mathrm{m}$ pore size for macrophages). The lower wells contained the chemotactic stimuli or DMEM as a negative control. In the case of neutrophils, after a 60-min incubation at $37^{\circ} \mathrm{C}$ in $5 \% \mathrm{CO}_{2}$, the filter was removed, fixed, and stained. In the case of macrophages, after 90 -min incubation at $37^{\circ} \mathrm{C}$ in $5 \% \mathrm{CO}_{2}$, the filter was removed, fixed, and stained. Filters for both cell types were mounted on slides and cells were counted using a fluorescent microscope (BIOREVO BZ-9000; Keyence, Osaka), respectively.
The dorsal venom was applied to a Concanavalin ASepharose column $(2 \mathrm{ml})$ equilibrated with $20 \mathrm{mM}$ Tris$\mathrm{HCl}$ buffer containing $0.4 \mathrm{M} \mathrm{NaCl}$ (pH7.4). The column was rinsed thoroughly with the same buffer and then eluted with $100 \mathrm{mM}$ methyl- $\alpha$-D-mannoside in the buffer at a flow rate of $20 \mathrm{ml} / \mathrm{h}$. The bound fraction (Con A fraction) eluted by methyl- $\alpha$-D-mannoside showed agglutinating and mitogenic activity. For purification, the Con A fraction was applied to a Phenyl Sepharose CL4B column $(2 \mathrm{ml})$ equilibrated with $16 \mathrm{mM}$ Tris- $\mathrm{HCl}$ buffer containing $2 \mathrm{M} \mathrm{NaCl}$ (pH 7.4). The sample was rinsed with the same buffer and then eluted with the same buffer containing $0.01 \mathrm{M} \mathrm{NaCl}$ at a flow rate of $20 \mathrm{ml} / \mathrm{h}$. The bound fraction eluted with $0.01 \mathrm{M} \mathrm{NaCl}$ (the PS fraction) showed a single discrete band corresponding to an apparent mass of $110 \mathrm{kDa}$ on native PAGE, exhibiting agglutinating activity. The PS fraction (the glycoprotein) was designated Karatoxin (2). The recovery of Karatoxin as the protein content was about $1 \%$ of the dorsal venom, and the biological activity of Karatoxin was about 40 times higher than that of the venom in terms of agglutinating activity in the presence of rabbit erythrocytes.

We previously reported that dorsal venom protein from $H$. rubripinnis showed weak agglutination with rabbit erythrocytes and the degranulation of rat mesenteric mast cells (11). The agglutination caused by the venom was inhibited with D-mannose treatment. The venom also induced the mitogenic activity of murine splenocytes in the dose range of 10 to $100 \mu \mathrm{g} / \mathrm{ml}$ (Fig. 2).

In this study, we reported the mitogenic and chemotactic activities of Karatoxin, a dorsal mannose-containing glycoprotein from H. rubripinnis (Figs. 2 and 3). Karatoxin is mainly composed of $76-$ and $30-\mathrm{kDa}$ subunits. The N-terminal 14 amino acid sequence of the $76-\mathrm{kDa}$ subunit was shown to be DQHDDxPxxAPDPG (2). The amino acid sequence of Karatoxin is unique and is not related to other fish venoms $(12,13)$. The $76-\mathrm{kDa}$ subunit of Karatoxin contains mannose moieties (data not shown). Now, we are analyzing the primary structure of Karatoxin, and the total RNA has been isolated from the dorsal spines of this fish (unpublished data). While Karatoxin $(1.25-10 \mu \mathrm{g} / \mathrm{ml})$ did not exhibit hemolytic activity in the presence of rabbit erythrocytes, it showed agglutinating activity with rabbit erythrocytes. This agglutination by Karatoxin was effectively inhibited by Dmannose (data not shown). As shown in Fig. 2, Karatoxin had potent mitogenic activity. The mitogenic activity of Karatoxin was about 100 times higher than that of the crude venom. On the other hand, larger doses of Karatoxin showed a decrease in mitogenic activity. The dual response to Karatoxin suggests that it may have wideranging effects. Furthermore, Karatoxin exhibited 
chemotactic activity in the presence of guinea-pig neutrophils and macrophages in a low-dose ranges $(0.625-5.0 \mu \mathrm{g} / \mathrm{ml})$ (Fig. 3). This is the first reported finding involving guinea-pig leukocytes. In the present study, we could not detect activity at the lowest dose of $0.1 \mu \mathrm{g} / \mathrm{ml}$ of Karatoxin. As shown in Fig. 3, guinea-pig neutrophils were more sensitive to Karatoxin than guineapig macrophages. Karatoxin may exhibit chemotactic activity through binding to D-mannose containing carbohydrates that are present on the surface of guinea-pig neutrophils and macrophages. Therefore, it appears that Karatoxin is likely to recognize different sets of D-mannose residues in guinea-pig neutrophils in comparison with macrophages. These results suggest that Karatoxin may be a valuable tool for analyses of the inflammation, differentiation, and development of cells. Thus, Karatoxin appears to be a unique lectin.

It has been proposed that the venoms of most poisonous fish are chemically and pharmacologically similar,
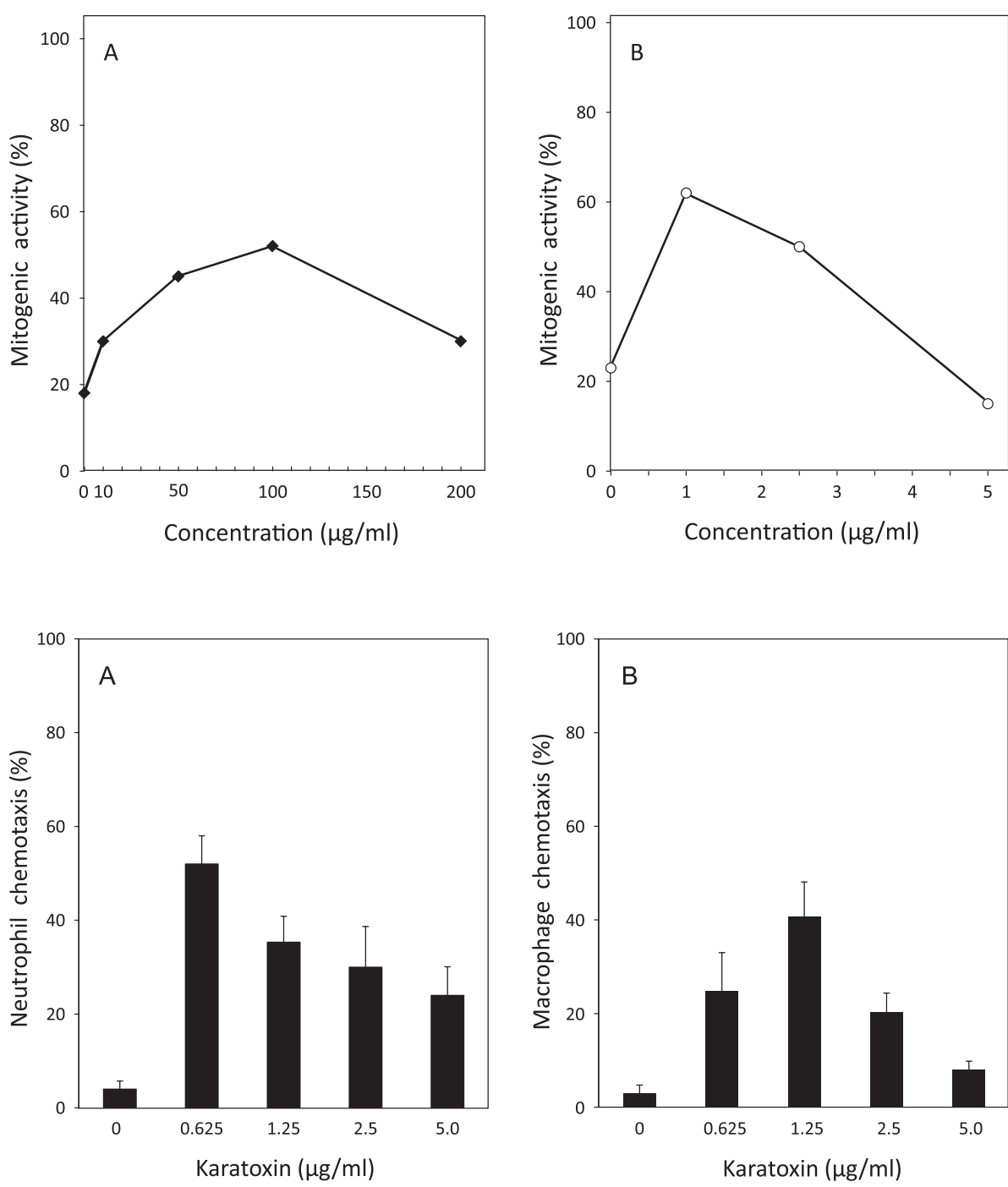

and that their effects differ only quantitatively. In addition, most piscine venoms exhibit hemolytic activity (14). In this study, Karatoxin showed no hemolytic activity. However, it exhibited not only cytotoxic activity (2), but also mitogenic activity, suggesting that the toxin may contribute to the local and systemic effects observed on envenomation such as severe pain, swelling, and fever. Moreover, Karatoxin had a chemotactic effect. Therefore, Karatoxin might affect inflammatory and immunomodulatory processes. Karatoxin appears to be a D-mannosebinding lectin. Based on the present results, Karatoxin may exhibit activity through binding to a specific carbohydrate chain, such as mannose moieties on the cell surface. More studies are necessary to clarify the biological activities of Karatoxin. Our data suggest that H. rubripinnis venom is a source of pharmacologically active substances such as lead compounds and compounds that have applications as research tools.
Fig. 2. Mitogenic effects of the crude venom (A) and Karatoxin (B) from $H$. rubripinnis on murine splenocytes. The splenocytes $\left(5 \times 10^{6}\right.$ cells $\left./ \mathrm{ml}\right)$ were incubated with the crude venom or Karatoxin for $68 \mathrm{~h}$ and then underwent continued incubation with MTT for $4 \mathrm{~h}$ in a $5 \% \mathrm{CO}_{2}$ humidified atmosphere. The mitogenic response to concanavalin A $(1.0 \mu \mathrm{g} / \mathrm{ml})$ was expressed as $100 \%$. Data represent the mean of two experiments of triplicate determinations.
Fig. 3. Effects of Karatoxin on neutrophil (A) and macrophage (B) chemotaxis. Neutrophils $\left(2 \times 10^{6} \mathrm{cell} / \mathrm{ml}\right)$ were incubated at $37^{\circ} \mathrm{C}$ for $60 \mathrm{~min}$, and macrophages $\left(1 \times 10^{6}\right.$ cells $\left./ \mathrm{ml}\right)$ were incubated at $37^{\circ} \mathrm{C}$ for 90 min with or without Karatoxin. The chemotactic response with FMLP $\left(10^{-7}\right.$ M) is expressed as $100 \%$. Data represent the mean \pm S.D. of $3-4$ experiments of triplicate determinations. 


\section{Acknowledgments}

The authors wish to express their appreciation to the late Dr. T. Nagasaka for graciously providing funds and constant encouragement. This work was supported in part by a Grant-in-Aid from The University of Tokushima.

\section{References}

1 Tange Y. Morphology of the poison apparatus in Japanese fish with comments on its toxicity. V. Poison apparatus in Hypodytes rubripinnis (Temminck et Schlegel). Yokohama Med Bull. 1954; 5:42-48.

2 Nagasaka K, Nakagawa H, Satoh F, Hosotani T, Yokoigawa K, Sakai K, et al. A novel cytotoxic protein, Karatoxin, from the dorsal spines of the redfin velvetfish, Hypodytes rubripinnis. Toxin Rev. 2009;28:260-265.

3 Barondes SH. Soluble lectins. A new class of extracellular proteins. Science. 1984;223:1259-1261.

4 Drickamer K. Two distinct classes of carbohydrate-recognition domains in animal lectins. Ann N Y Acad Sci. 1988;263:95579560.

5 Giga Y, Ikai A, Takahashi K. The complete amino acid sequence of a lectin from the coelomic fluid of the sea urchin Anthrocidaris crassispina: homologies with mammalian and insect lectins. J Biol Chem. 1987;262:6197-6203.

6 Hatakeyama T, Nagatomo H, Yamasaki N. Interaction of the hemolytic lectin CEL-III from the marine invertebrate Cucumaria echinata with the erythrocyte membrane. J Biol Chem. 1995; 270:3560-3564.

7 Nakagawa H, Tanigawa T, Tomita K, Tomihara Y, Araki Y, Tachikawa E. Recent studies on the pathological effects of purified sea urchin toxins. J Toxicol Toxin Rev. 2003;22:633-649.

8 Satoh F, Nakagawa H, Yamada H, Nagasaka K, Nagasaka T, Araki Y, et al. Fishing for bioactive substances from scorpionfish and some sea urchins. J Nat Toxins. 2002;11:297-304.

9 Bradford MM. A rapid sensitive method for the quantification of microgram quantities of protein utilizing the principle of proteindye binding. Anal Biochem. 1976;72:248-254.

10 Nakagawa H, Yamaguchi C, Hayashi H. Biologically active substances from sea urchins. J Nat Toxins.1997;6:193-202.

11 Nakagawa H, Yamaguchi C, Yamada H, Nagasaka K, Nagasaka T. Preliminary study on the venom of scorpionfishi, Hypodytes rubripinnis. Comp Physiol Biochem. 1995;12:339.

12 Ueda A, Suzuki M, Honma T, Nagai H, Nagashima U, Shiomi K, et al. Purification, properties and cDNA cloning neoverrcotoxin (neoVTX), hemolytic lethal factor from the stonefish Synanceia venom. Biochim Biophys Acta. 2006;1760:1713-1722.

13 Nakagawa H, Edo K, Ashida K, Nakanishi A, Sakai H, Nagasaka $\mathrm{K}$, et al. Partial purification of dorsal lectins of the Japanese devil scorpionfish, Inimicus japonicas (abstract). J Pharmacol Sci. 2008;106:Suppl I:208P.

14 Church JE, Hodgson WC. The pharmacological activity of fish venoms. Toxicon. 2002;40:1083-1093. 